\title{
Reliability of the Wii Balance Board in kayak
}

\author{
Stefano Vando ${ }^{1}$ \\ Guillaume Laffaye ${ }^{2}$ \\ Daniele Masala ${ }^{1}$ \\ Lavinia Falese ${ }^{1}$ \\ Johnny Padulo3,4
}

1 Department of Human, Social and Health Sciences University of Cassino and Southern Lazio, Italy

2 UR CIAMS, Motor Control and Perception Group, Sport Sciences Department, Université Paris-Sud, France

3 University eCampus, Novedrate, Italy

4 Tunisian Research Laboratory "Sports Performance Optimization" National Center of Medicine and Science in Sport, Tunis, Tunisia

Corresponding author:

Johnny Padulo

University eCampus

Via Isimbardi, 10

22060 Novedrate, Italy

E-mail:sportcinetic@gmail.com

\section{Summary}

Background: the seat of the kayaker represent the principal contact point to express mechanical Energy.

Methods: therefore we investigated the reliability of the Wii Balance Board measures in the kayak vs. on the ground.

Results: Bland-Altman test showed a low systematic bias on the ground $(2.85 \%)$ and in kayak $(-2.13 \%)$ respectively; while $\mathbf{0 . 9 9 6}$ for Intra-class correlation coefficient.

Conclusion: the Wii Balance Board is useful to assess postural sway in kayak.

The Wii Balance Board (WBB) showed itself as good device to assess postural sway ${ }^{1,2}$. In additional there aren't ecological field studies ${ }^{3}$ that assessed postural sway in kayaker ${ }^{4}$. Besides, the power developed by the kayak padding is shifted to the kayak through applications against a seat ${ }^{5}$. Considering the extensive of this device in sport 6,7 we believe that WBB can be used also in kayak. For this aim we compare the reliability of the measures of WBB on ground, on WBBm modified as the seat of the kayak on ground and WBBm on kayak in water.

Eight international male kayakers (age 24.5 \pm 2.8 years, body height $1.81 \pm 0.1 \mathrm{~m}$, body mass $78 \pm 3.6 \mathrm{~kg}$, BMI: $24 \pm 0.2 \mathrm{~kg} \cdot \mathrm{m}^{-2}$ ) performed on WBB (Fig. 1) in randomized order in seated position (to emulate kayak place on ground) and in water for to assess postural sway accordingly to MLTJ guideline ${ }^{8}$. The trials (WBBWBBm-WBBm on kayak) with Wii balance board was selected for each athlete (Latin square design ${ }^{9}$ ) for two sets (test- retest) on WBB on ground (Fig. 1A) and on WBBm (modified as the seat of the kayak on ground "Seat Sensor"). While other two (test- retest) sessions was performed with a WBBm on kayak $\left(\mathrm{Nelo}^{\mathrm{TM}} 12 \mathrm{~kg}\right.$ ) in water (Fig. 1B). The duration time for each session was 25 " with 2 min between sets ${ }^{10}$. Spss 19 was used for the reliability ${ }^{11}$ of the measures with Intra-class Correlation Coefficient (ICC) and Bland - Altman tests of the centre of pressure (COP) velocity $\left(\mathrm{mm} \cdot \mathrm{s}^{-1}\right)$. While the three different conditions (WBB-WBBm-WBBm on kayak) was analyzed with an Univariate ANOVA and "Bonferroni" post-hoc analysis. The significant effect was fixed at $p<0.05$.

ANOVA showed significant effect on the three conditions $F=9.121$ with $p<0.001$. The path was $19.01 \pm 1.35$ and $16.64 \pm 1.41 \mathrm{~mm} \cdot \mathrm{s}^{-1}$ in WBB and WBBm respectively $(p>0.05)$, differently in kayak where there is less stability the path velocity was more higher $(33.81 \pm 14.96$ $\left.\mathrm{mm} \cdot \mathrm{s}^{-1}\right)$ with $\mathrm{p}=0.008 \mathrm{vs}$. WBB $(78 \%)$, and $\mathrm{p}=0.002 \mathrm{vs}$. WBBm (103\%). While the ICC was $0.932-0.902-$ 0.996 with $<3 \%$ between repeated measures in WBB WBBm and WBBm in kayak respectively. Bland-Altman shows good agreement (WBB) with a low systematic

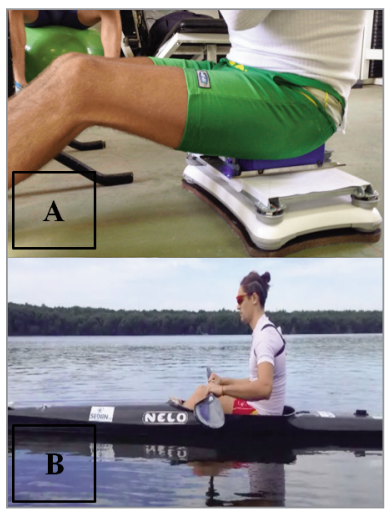

Figure $1 \mathrm{~A}, \mathrm{~B}$. Wii Balance Board on the ground and in kayak. 


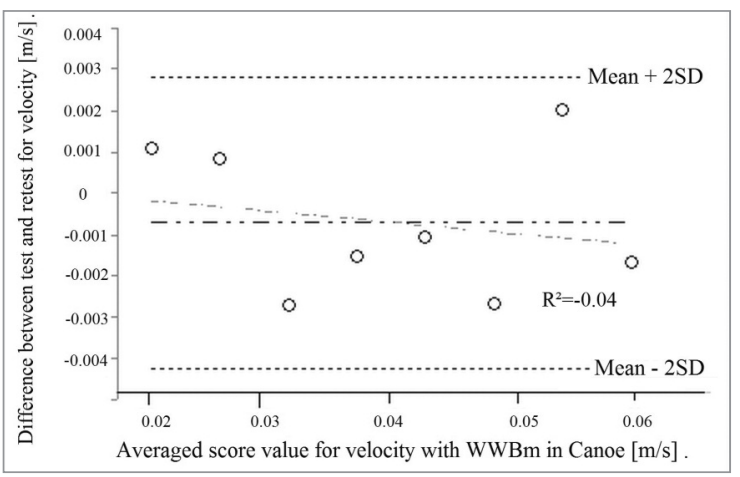

Figure 2. Bland-Altman plotting with limits of agreement between velocity of Centre of pressure between test and retest.

bias $\left(-0.29 \mathrm{~mm} \cdot \mathrm{s}^{-1}\right.$ or $\left.-1.49 \%\right)$ and low confidence interval $(-1.69<95 \% \mathrm{Cl}<1.11)$ and the variable is homoscedastic $(r=0.02)$. For WWBm, the Bland-Altman (Fig. 2) shows good agreement with a low systematic bias $\left(0.46 \mathrm{~mm} \cdot \mathrm{s}^{-1}\right.$ or $2.85 \%$ for WWBm and $-0.72 \mathrm{~mm} \cdot \mathrm{s}$ 1 or $-2.13 \%$ for WWBm in kayak respectively) and moderate confidence interval $(-1.05<95 \% \mathrm{Cl}<1.97$ for WWBm and $-4.24<95 \% \mathrm{Cl}<2.80$ for WWBm in kayak respectively) and the variables are homoscedastic $(r<0.1)$. Though the path velocity showed in this new experimental approaches in kayak was very high moreover the reliability was very strong 0.996 . Moreover, this is the first study assessing postural sway reliability in kayak by a new tool low cost "Wii Balance Board". Considering the accurate methodological approach and the good reliability of the measures, this article can be encourage the young scientific researcher to assess postural sway during the kayak race to improve the balance and force during paddle strokes's phases ${ }^{12}$.

\section{References}

1. Clark RA, Bryant AL, Pua Y, McCrory P, Bennell K, Hunt M. Validity and reliability of the Nintendo Wii Balance Board for assessment of standing balance. Gait Posture. 2010;31(3):307310.

2. Kalron A, Frid L. Nintendo Wii virtual reality game improves short term balance capabilities in multiple sclerosis patients: a pilot quasi-experimental study. J Phys Ther. 2012;5(2):54-62.

3. Jobson SA, Nevill AM, Palmer GS, Jeukendrup AE, Doherty $M$, Atkinson $G$. The ecological validity of laboratory cycling: Does body size explain the difference between laboratory- and field-based cycling performance? J Sports Sci. 2007;25(1):39 .

4. Michael JS, Smith R, Rooney KB. Determinants of kayak paddling performance. Sports Biomech. 2009;8(2):167-179.

5. Shephard RJ. Science and medicine of canoeing and kayaking. Sports Med. 1987;4(1):19-33.

6. Vando S, Filingeri D, Maurino LC, Chaabene H, Bianco A, et al. Postural Adaptations in Preadolescent Karate Athletes Due to a one Week Karate Training Camp. J Hum Kinet. 2013;38: 45-52.

7. Vando S, Unim B, Cassarino SA, Padulo J, Masala D. Effectiveness of perceptual training - proprioceptive feedback in a virtual visual diverse group of healthy subjects: a pilot study. Epidemiology Biostatistics and Pubblic Health. 2013;10(2): e8844-1-e8844-10.

8. Padulo J, Oliva F, Frizziero A, Maffulli N. Muscles, Ligaments and Tendons Journal. Basic principles and recommendations in clinical and field science research. MLTJ. 2013;4:250-252.

9. Padulo J, Granatelli G, Ruscello B, D'Ottavio S. The place kick in rugby. J Sports Med Phys Fitness. 2013;53(3):224-231.

10. Scoppa F, Capra R, Gallamini M, Shiffer R. Clinical stabilometry standardization: basic definitions-acquisition intervalsampling frequency. Gait Posture 2013;37(2):290-292.

11. Atkinson G, Nevill AM. Statistical methods for assessing measurement error (reliability) in variables relevant to sports medicine. Sports Med. 1998;26(4):217-238.

12. Franklin RC, Leggat PA. The epidemiology of injury in canoeing, kayaking and rafting. Med Sport Sci. 2012;58:98-111. 